\title{
Sex Differences in Long-Term Survival after a First Stroke with Intravenous Thrombolysis: Ebrictus Study
}

\author{
José Luis Clua-Espuny ${ }^{a}$ Rosa Ripolles-Vicente ${ }^{a}$ Teresa Forcadell-Arenas ${ }^{a}$ \\ Vicente Francisco Gil-Guillen ${ }^{c}$ Maria Lluïsa Queralt-Tomas ${ }^{a}$ \\ María Antonia González-Henares ${ }^{a}$ Anna Panisello-Tafalla ${ }^{a}$ Carlos López-Pablob \\ Jorgina Lucas-Nolla on behalf of the Ebrictus Group \\ a Health Department, Catalonian Health Institute, SAP Terres de l'Ebre, Generalitat de Catalunya, \\ and ${ }^{b}$ Department of Research, ICS Terres de I'Ebre, Institut Universitari d'Investigació en Atenció \\ Primària (IDIAP) Jordi Gol-IISPV, Tortosa, and ${ }^{\mathrm{C} C l i n i c a l ~ E v i d e n c e ~ B a s e d ~ M e d i c i n e ~ a n d ~ E m o t i o n a l ~}$ \\ Department, Miguel Hernández University, Family and Community Speciality, Elche, Spain
}

Key Words

Acute ischemic stroke $\cdot$ Intravenous thrombolysis · Sex · Incidence · Survival · Mortality

\begin{abstract}
Background: A number of large trials have confirmed the benefits of thrombolysis in acute stroke, but there are gender differences. We sought to examine the relationship between sex and outcome after thrombolysis. Methods: This was a prospective cohort study including 1,272 incident ischemic strokes (597 in women) from April 1, 2006 to December 31, 2014. Statistical approaches were used for analyzing survival outcomes and their relationship with thrombolysis therapy. Results: The death rates were lower $(p=0.003)$ in the thrombolysis therapy group with an incidence ratio of 0.57 (95\% CI 0.39-0.83). 113 (8.8\%) patients (53 women) received thrombolysis. They were significantly younger (69.2 \pm 12.7 vs. $73.9 \pm 12.5$ years; $p<0.001)$, had higher NIHSS score $(12.7 \pm 6.3$ vs. $7.3 \pm 7.0 ; p<0.001)$, spent more days in hospital $(10.4 \pm 8.3$ vs. $8.3 \pm 7.9 ; p<0.001)$, and had a higher average Barthel score at discharge $(85.5 \pm 24.4$ vs. $79.2 \pm 28.6 ; p=0.023)$. The male/female incidence ratio showed a significant decrease $(p=0.01)$ in the incidence of mortality in women and a better Barthel score. The thrombolysis improved the survival in the overall group with thrombolysis versus without thrombolysis $(p=0.028)$, in women versus in men with thrombolysis $(p=0.023)$, and in women with thrombolysis versus in those without thrombolysis $(p<0.001)$ but not in men with thrombolysis versus in those without thrombolysis $(p=0.743)$. The protective factors as re-
\end{abstract}

Teresa Forcadell-Arenas

Health Department, CAP Ampolla, Generalitat de Catalunya

Manuel Ferrer Square

ES-43895 L'Ampolla (Spain)

E-Mail t_forcadell@ hotmail.com 
gards mortality were thrombolysis therapy (95\% CI 0.37-0.80; $p=0.002)$, Barthel score $\geq 60$ (95\% CI 0.81-0.94; $p=0.002)$, and cardiovascular secondary prevention 1 year after stroke (0.13, 95\% CI 0.06-0.28). Conclusions: The stroke death rates were lower in women after thrombolysis treatment and suggest significant benefit for women in this setting. The overall benefit on survival of the patients treated with thrombolysis might be explained by the beneficial effect of the thrombolysis on the women.

(C) 2015 The Author(s)

Published by S. Karger AG, Basel

\section{Background}

Previous reports [1-6] concerning sex-related differences in stroke management and outcome are inconsistent and sometimes difficult to interpret, and so the reasons for gender disparities in stroke outcome have remained unclear. Functional outcomes and quality of life after stroke are consistently poorer in women despite adjustment for baseline differences in age and prestroke function, and the fact that comorbidities and clinical outcomes were not different between women and men [3,7]. Once the reasons for these differences are better understood, intervention might be possible to help provide the best care for all patients. This work is a continuation and extension of the Ebrictus Study [8-10]. Prior work has suggested sex-based differences in thrombolytic therapy in subjects with acute stroke [11]. We explored whether sex might modify the effect of thrombolysis on survival and functional outcomes in patients with acute ischemic stroke [12] beyond the usually evaluated time period of 6 months after stroke and compared this with the group without thrombolytic treatment.

\section{Methods}

This is a prospective cohort study including 1,272 incident strokes (597 in women) from April 1, 2006 to December 31, 2014. Statistical approaches were used to analyze survival outcomes. It is a longitudinal study of a population-based cohort of all registered cases of a first episode of stroke that occurred between April 1, 2006 and December 31, 2014 in Baix Ebre and Montsia (Tarragona, Spain).

\section{Demographic Patterns and Epidemic Characteristics}

In the last two decades the region has been characterized by negative growth and a higher aging factor. The population aged $>80$ years has increased $66 \%$ in the period from 1986 to 2006 , comprising $3.5-5.9 \%$ of the overall population. Life expectancy at birth is 81.34 years globally, 78.26 years for men and 84.74 years for women.

\section{Case Definition}

The definition of stroke corresponds to that set by the World Health Organization. Patients were included by using the automated operation of the database of patients with a diagnosis code of stroke (I60-I69). Once the inclusion criteria were confirmed, data from the protocols of the clinical history of primary care (e-cap) and hospital records for any of the defined services (e-SAP) were systematically reviewed. All primary care centers and hospitals in the area were included.

The inclusion criteria were: age $\geq 15$ up to $\leq 90$; usual residence in the area and/or assignment to any of the participating primary care centers for 5 years at the time of the stroke episode; a diagnosis of stroke explicitly recorded in their medical record at any of the 
registration systems in the health centers of the area; it should be a first stroke episode, and relevant episode information should be available in clinical records: (a) outpatient clinic, (b) hospital clinic, or (c) access to medical/sociosanitary reports.

The variables on which information was collected were grouped as follows: sociodemographic; clinics: type (ischemic or hemorrhagic stroke) and event date (day/month/year); NIHSS score on admission; whether or not there was thrombolytic therapy; duration of hospital stay; hospital discharge destination (home, higher-level acute hospital, long-term care hospital, death and date thereof); pre- and poststroke functional autonomy [the Barthel score was classified as follows: $<20$ (total dependence), 20-35 (severe dependence), 40-55 (moderate dependence), $\geq 60$ (mild dependence), or 100 (independence) registered for preepisode and for discharge in the medical history of the patient, the hospital, or the primary care center]; functional status of the patient at discharge: death, home-autonomous, home address caregiver, referral to another acute hospital, or convalescent center (temporary or long-term stay), and vital status (alive/dead) of the patient, specifying the date (day/month/ year) of death, if any.

\section{Statistical Analysis}

Computerized statistical analysis was undertaken with the following: (1) descriptive basic statistics and standard deviation of key variables stratified by age and sex and (2) differences in functional outcome and its evolution before and after the episode determined the possible effects on mortality and different residual deficits categorized with the statistical Cox regression model. Mortality should be interpreted as overall mortality and cause-specific, no stroke. Patients who died during hospitalization or within the 1st month are considered 'immediate death'. During follow-up the deceased are described as 'subsequent mortality'. The analysis and processing of data was performed using the SPSS 11.5 statistical package for Windows.

\section{Results}

We analyzed 1,272 consecutive patients from our local prospective stroke database who suffered first-ever strokes (men 53.1\%, p = 0.008) from April 1, 2006 to December 31, 2014. The average age was $73.9 \pm 12.5$ years $(25-90)$. The men had a significantly $(p<0.001)$ lower mean age than women and had a lower NIHSS score $(\mathrm{p}<0.001)$. The average follow-up was $3.6 \pm 3.7$ years. The male/female incidence ratio was 1.004 (95\% CI $0.860-1.173)$. Of the total patients, $10.32 \%$ died in the 1 st month and $42.9 \%$ at 5 years. There were no differences in adjusted mortality rates between the sexes. The survival probability was 0.47 ( $95 \%$ CI 0.39 $0.55) 5$ years after stroke.

1,160 patients (46.9\% women) were not treated with thrombolytic therapy (table 1 ). Compared with those with thrombolysis, they were significantly older, with less severe stroke by NIHSS score, spent fewer days in hospital, with lower Barthel score after stroke, with fewer referrals to acute hospitals for complications, and a higher mortality incidence. The survival probability was 0.39 (95\% CI 0.33-0.45) 5 years after stroke. In this group the women were significantly older, with a more severe stroke by the NIHSS score, more days in hospital, the lowest Barthel score, the highest percentage of patients with a Barthel score $<60$ after stroke, and a survival probability lower than that in men (incidence ratio $=1.20,95 \%$ CI 1.00-1.42). The mortality among men with a Barthel score $<60$ was higher (incidence ratio $=2.27,95 \%$ CI 1.10-4.69) than that in women.

$113(8.9 \%)$ patients (53 women) received thrombolysis. They were younger, suffered more severe strokes, and had lower mortality and higher Barthel score after stroke. The 


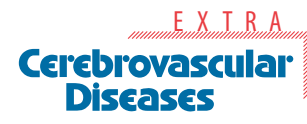

Clua-Espuny et al.: Sex Differences in Long-Term Survival after a First Stroke with Intravenous Thrombolysis: Ebrictus Study

Table 1. General characteristics (Ebrictus 2006-2014)

\begin{tabular}{lcccc}
\hline Variables & Men & Women & p & All \\
\hline Ischemic stroke, n (\%) & $675(53.1)$ & $597(46.9)$ & 0.008 & 1,272 \\
Mean age, years & $71.7 \pm 12.4$ & $76.3 \pm 12.1$ & $<0.001$ & $73.9 \pm 12.5$ \\
Average NIHSS score & $6.4 \pm 6.3$ & $8.7 \pm 7.6$ & $<0.001$ & $7.3 \pm 7.0$ \\
Average hospital stay, days & $7.9 \pm 7.9$ & $8.9 \pm 7.9$ & 0.034 & $8.3 \pm 7.9$ \\
Average Barthel score at discharge & $84.5 \pm 24.3$ & $72.3 \pm 31.7$ & $<0.001$ & $79.2 \pm 28.6$ \\
Barthel score <60, \% & 12.0 & 33.5 & $<0.001$ & 21.7 \\
Mortality incidence rate in people with Barthel <60 & & & \\
$\quad$ (95\% CI), n/100 cases/year & $12(10.04-33.9)$ & $19(5.13-13.32)$ & 0.02 & $31(7.40-15.47)$ \\
Cumulated survival risk at 5 years & 0.45 & 0.33 & n.s. & 0.39 \\
Mortality incidence rate (95\% CI), n/100 cases/year & $11.04(9.7-12.51)$ & $13.25(11.7-14.9)$ & n.s. & $12.1(11.1-13.2)$ \\
\hline Thrombolysis treatment, n (\%) & $60(8.9)$ & $53(8.9)$ & 0.537 & $113(8.9)$ \\
Mean age, years & $69.3 \pm 12.9$ & $69.06 \pm 12.5$ & 0.893 & $69.2 \pm 12.7$ \\
Average NIHSS score & $13.23 \pm 6.4$ & $12.5 \pm 6.2$ & 0.55 & $12.7 \pm 6.3$ \\
Average hospital stay, days & $9.8 \pm 11.6$ & $11.4 \pm 9.5$ & 0.54 & $10.4 \pm 10.6$ \\
Average Barthel score at discharge & $83.9 \pm 25.0$ & $87.2 \pm 24.1$ & 0.591 & $85.5 \pm 24.4$ \\
Barthel score <60, \% & 15.1 & 6.4 & 0.47 & 10.9 \\
Cumulated survival risk at 5 years & 0.41 & 0.70 & 0.003 & 0.55 \\
Incidence rate (95\% CI), n/100 cases/year & $13.4(7.8-21.5)$ & $4.2(1.5-9.2)$ & 0.01 & $8.5(5.4-12.8)$ \\
\hline
\end{tabular}

${ }^{\mathrm{a}} \mathrm{p}>0.05$.

survival curves showed lower mortality (OR $=0.67,95 \%$ CI $0.47-0.95, \mathrm{p}=0.028$ ) among those with than those without thrombolysis. The survival probability was 0.55 (95\% CI $0.41-0.70$ ) 5 years after stroke. Thrombolysis improved the survival in the overall group with thrombolysis versus in that without (p 0.028); in women (fig. 1) versus men with thrombolysis ( $p<0.001$ ), and in women (fig. 2) with thrombolysis versus in those without ( $p<0.001)$ but not in men with thrombolysis (fig. 3 ) versus in those without $(p=0.743)$. The women treated with thrombolysis had the best Barthel score, with a lower prevalence of moderate prevalence and the longest survival outcome.

The overall survival probability among women was $0.70 \pm 0.06$ and among men $0.41 \pm$ $0.02(p=0.012)$. The incidence density of mortality for the overall group was $8.5 / 100$ cases/ year follow-up (95\% CI 5.4-12.8); in the group of women it was $4.2 / 100$ cases/year $(95 \%$ CI 1.5-9.2) and in the group of men 13.4/100 cases/year (95\% CI 7.8-21.5). An increased risk in men compared to women was shown (incidence ratio $=3.2,95 \% \mathrm{CI} 1.2-8.0$ ). The factors significantly associated with survival were gender (woman OR $=1.12,95 \%$ CI 1.05-1.20) and were treated with secondary cardiovascular prevention 1 year after stroke $(0.13$, CI 95\% 0.06-0.28). The NIHSS is an independent predictor of functional outcome and correlates with the Barthel score after stroke $(p=0.022)$ and survival $(p<0.001)$ : the highest NIHSS score has the highest risk of Barthel score of $\leq 60$ (OR $=1.14$, CI 95\% 1.08-1.20). A Barthel score $<60$ is a predictor of long-term mortality. Its incidence rate was 2.75 (CI 95\% 1.82-4.14, p < $0.001)$.

The Barthel score before stroke was close to full independence $(92.9 \pm 17.7)$ and was significantly $(\mathrm{p}<0.001)$ higher in men $(94.9$ vs. 90.4$)$ than in women. $79.1 \%$ were independent before the stroke and only 5.5\% had a moderate or greater dependence earlier. The percentage of patients with moderate or greater dependence increased up to $22.5 \%$. The relative risk reduction was $46 \%$, the absolute risk reduction was $9.4 \%$ to get a reduction in the number of people with the outcome of a Barthel score $<60$ at discharge, and the number 
Fig. 1. Survival curve by gender: all with thrombolysis.

Fig. 2. Survival curve of the women: with versus without thrombolysis.

Fig. 3. Survival curve of the men: with versus without thrombolysis.

\section{DOI: $10.1159 / 000440734$ \\ (c) 2015 The Author(s). Published by S. Karger AG, Basel www.karger.com/cee}

Clua-Espuny et al.: Sex Differences in Long-Term Survival after a First Stroke with Intravenous Thrombolysis: Ebrictus Study
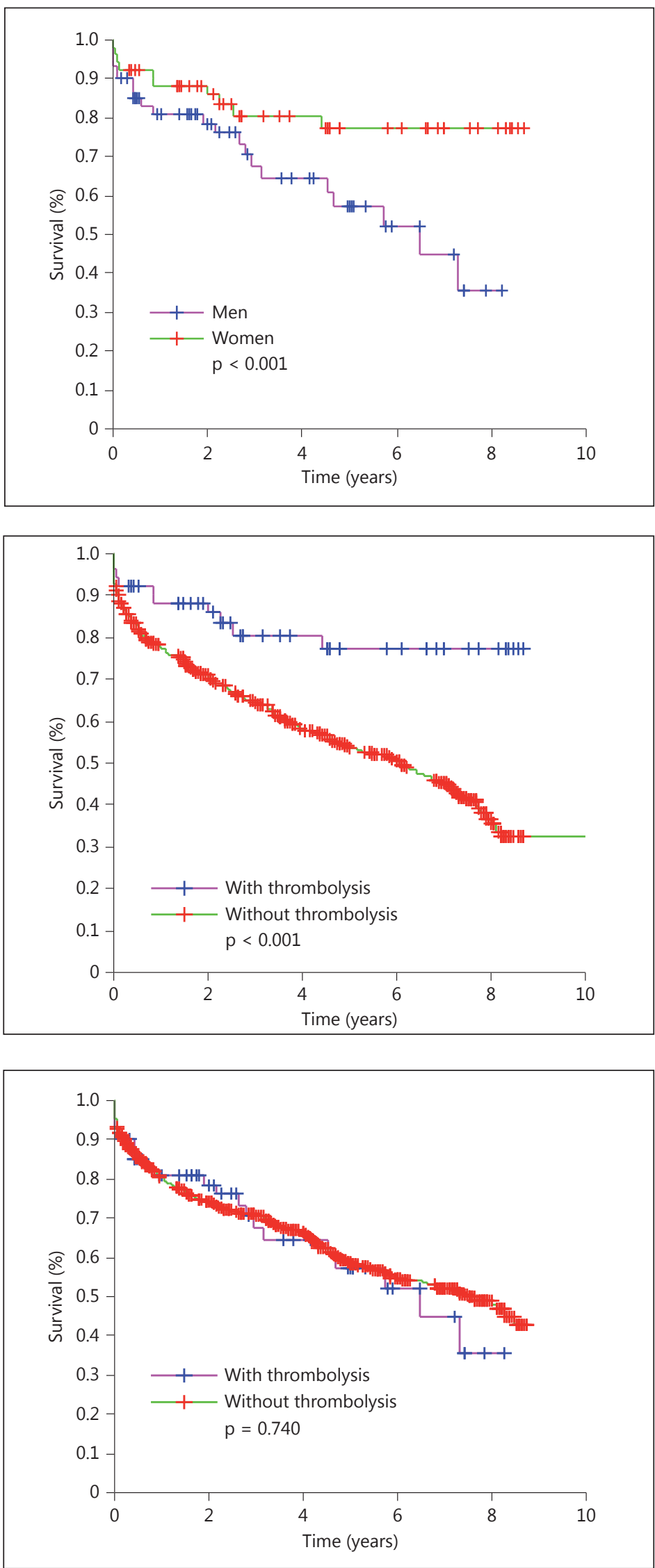

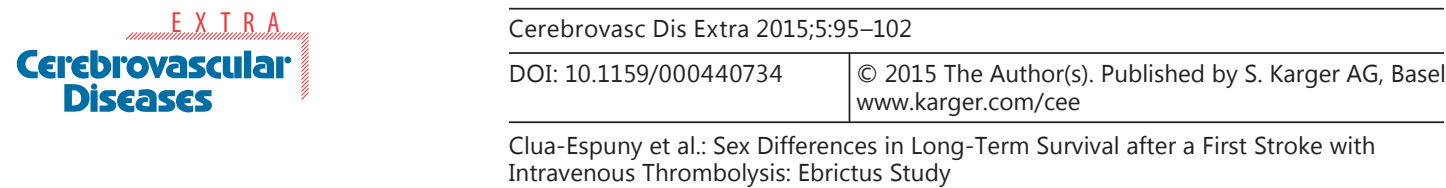

needed to treat was 10 to get another result with a Barthel score $>60$ at discharge. Age (OR 1.07, 95\% CI 1.01-1.13) and NIHSS score (OR 1.1, 95\% CI 1.04-1.18) were identified as the only independent prognostic protector factors regarding dependence (Barthel $<60$ ).

\section{Discussion}

The results from this study contribute evidence that intravenous thrombolysis may modify the survival and recovery expected in the natural course of an ischemic stroke, with possibly a larger beneficial treatment effect in women when compared to men. We found that exposure to thrombolysis in women is much more beneficial than in men. The women treated with thrombolysis got the best Barthel score, the lowest dependence prevalence, and the longest survival outcome. We cannot say the same of the men or at least there is no such evidence. Some authors [13] had attempted to explain that multifactorial reasons were responsible for these observed differences in clinical stroke between men and women. Some may result from differences in socioeconomic factors such as advanced age, comorbid illnesses, or decreased social support [14], but clearly new data on the effects of response to thrombolysis suggest that there are biological differences. Men have a higher risk of any cause death than women up to 85 years of age, but changes in survival after stroke differ by sex and it is unclear whether poststroke differences reflect differential effects of stroke per se or differences in the prestroke situation. The challenge is whether these data can achieve better health outcomes by selecting patients with a more favorable risk versus thrombolytic profile, especially among men.

Former studies reported that mainly outcome and mortality were comparable between the two sexes after 3 months, but found a higher mortality in women and, just the opposite, a higher mortality in men according the statistical tool used [15] or when different hemispheres were affected [16]. The age, the higher cardiovascular risk, the secondary prevention, the clinical severity, and the functional residual capacity measured by Barthel's scale can all be considered as prognostic factors after the stroke episode $[17,18]$. The disparity in stroke outcome is not explained by differences in the ischemic lesion volume or the presence of intracranial artery occlusions [18], but the thrombolytic therapy seems to add greater benefit in women than in men. This gender effect seems go on beyond the benefit of functional outcome and the usual gender difference in outcome. In conclusion, women had longer survival and improved functional results with thrombolytic therapy after acute ischemic stroke independent of admission NIHSS scores, Barthel score, and age. The lower benefit of the male gender on outcome indicates that further additional work is needed to maximize outcomes in as many patients as possible. A greater understanding of the differences and similarities between males and females with respect to the risk factors, previous cardiovascular risk factors $[10,13,17-19]$, previous physical or mental condition, response to acute stroke therapies, and recovery will hopefully lead to better outcomes in both sexes in the future.

Thrombolytic treatment for acute ischemic stroke improves the prognosis but is time dependent. This treatment presents unique challenges for the development of tools [20, 21] to support decision-making as regards optimizing treatment rates by assisting clinicians to weigh up the potential net benefit in treating any individual patient; to support clinicians in communicating accurate information on risks/benefits and prognosis to patients, and to seamlessly support different approaches to decision-making about thrombolysis such as the thrombectomy [22].

In this new era of acute stroke therapy [23], this research makes available new scientific information on clinical data, confirms at least a larger beneficial treatment effect in women 
Clua-Espuny et al.: Sex Differences in Long-Term Survival after a First Stroke with Intravenous Thrombolysis: Ebrictus Study

when compared to men in the form of better health outcomes and lower mortality, dealing with the doubt whether men actually have some benefit in their incidence of mortality, indicating the need to develop specific types of interventions to improve stroke outcomes in men [8].

There are some limitations as regards our study. First, it was a retrospective review of medical records. As sex is a nature-determined factor, primary randomization was obviously not possible. Our results are limited to patients treated with thrombolysis. Thus, factors influencing the outcome after stroke such as sociodemographic parameters were not investigated. When analyzing a complex intervention, such as the principal characteristics of existing practices, it is vital to consider the management of information involved in the process as key elements that should be common and shared between hospitals and communities to grant a continuity of care.

\section{Conclusion}

Thrombolysis reduces the mortality and disability after the first stroke episode, especially among women, and secondary cardiovascular prevention reduces the risk of mortality 7 times. These results suggest a significant major probability of survival among women that increases progressively beyond 3 months.

The overall benefit on the survival of the patients treated with thrombolysis might be explained with the beneficial effect of thrombolysis on the women. The challenge is whether these data can achieve better health outcomes through the selection of patients with a more favorable risk versus thrombolytic profile.

\section{Acknowledgements}

We would like to thank the Clinical Evidence Based Medicine and Emotional Department, Miguel Hernández University, Elche, Spain for its support in developing this research.

\section{Disclosure Statement}

The authors declare that they have no competing interests.

\section{References}

$>1$ Eriksson M, Glader E-L, Norrving B, Terént A, Stegmayr B: Sex differences in stroke care and outcome in the Swedish national quality register for stroke care. Stroke 2009;40:909-914.

-2 Förster A, Gass A, Kern R, Wolf ME, Ottomeyer C, Zohsel K, Hennerici M, Szabo K: Gender differences in acute ischemic stroke: etiology, stroke patterns and response to thrombolysis. Stroke 2009;40:2428-2432.

-3 Lorenzano S, Ahmed N, Falcou A, Mikulik R, Tatlisumak T, Roffe C, Wahlgren N, Toni D; on behalf of the SITS Investigators: Does sex influence the response to intravenous thrombolysis in ischemic stroke? Stroke 2013; 44:3401-3406.

-4 Gargano JW, Reeves MJ; for the Paul Coverdell National Acute Stroke Registry Michigan Prototype Investigators: Sex differences in stroke recovery and stroke-specific quality of life: results from a statewide stroke registry. Stroke 2007;38:2541-2548.

-5 Niewada M, Kobayashi A, Sandercock PA, Kaminski B, Czlonkowska A: Influence of gender on baseline features and clinical outcomes among 17,370 patients with confirmed ischaemic stroke in the international stroke trial. Neuroepidemiology 2005;24:123-128.

6 Kent DM, Buchan AM, Hill MD: The gender effect in stroke thrombolysis. Of CASES, controls, and treatmenteffect modification. Neurology 2008;71:1080-1083. 
7 Meseguer E, Mazighi M, Labreuche J, Arnaiz C, Cabrejo L, Slaoui T, Guidoux C, Olivot J-M, Abboud H, Lapergue B, Raphaeli G, Klein IF, Lavallée PC, Amarenco P: Outcomes of intravenous recombinant tissue plasminogen activator therapy according to gender: a clinical registry study and systematic review. Stroke 2009;40:20042010.

-8 Clua-Espuny JL, Piñol-Moreso JL, Panisello-Tafalla A, Lucas-Noll J, Gil-Guillen VF, Orozco-Beltran D, QueraltTomas ML: Estudio Ebrictus. Resultados funcionales, supervivencia y años potenciales de vida perdidos después del primer episodio de ictus (in Spanish). Aten Primaria 2012;44:223-231.

-9 Clua-Espuny JL, Piñol-Moreso JL, Gil-Guillén JF, Orozco-Beltran D, Panisello-Tafalla A, Lucas-Noll J: La atención sanitaria del ictus en el área Terres de l'Ebre desde la implantación del Código Ictus: Estudio Ebrictus. Med Clín 2012;138:609-611.

10 Clua-Espuny JL, Garcés-Redondo M, Lucas-Noll J, Panisello-Tafalla A, Queralt-Tomas LL: Stroke epidemiology, survival and disability in a Mediterranean population according Malmgren's criteria. Ebrictus Cohort. Ann Vasc Med Res 2014;1:1004.

-11 Clua-Espuny JL, Ripolles-Vicente R, Lopez-Pablo C, Panisello-Tafalla A, Lucas-Noll J, Calduch-Noll C, GonzálezHenares MA, Queralt-Tomas ML: Diferencias en la supervivencia después de un episodio de ictus tratado con fibrinólisis. Estudio Ebrictus (in Spanish). Aten Primaria 2015;47:108-116.

12 Queralt-Tomas MLL: Coordination strategies of care across stroke recovery: proposals for nursing interventions in primary care. Clin Nurs Stud 2015;3:81.

13 Turtzo LC, McCullough LD: Sex differences in stroke. Cerebrovasc Dis 2008;26:462-474.

14 Mehndiratta P, Wasay M, Mehndiratta MM: Implications of female sex on stroke risk factors, care, outcome and rehabilitation: an Asian perspective. Cerebrovasc Dis 2015;39:302-308.

15 Lorenzano S, Ahmed N, Falcou A, Mikulik R, Tatlisumak T, Roffe C, Wahlgren N, Toni D; FESO on behalf of the SITS Investigators: Does sex influence the response to intravenous thrombolysis in ischemic stroke?: answers from safe implementation of treatments in Stroke-International Stroke Thrombolysis Register. Stroke 2013; 44:3401-3406.

16 Hametner C, Ringleb P, Kellert L: Sex and hemisphere - a neglected, nature-determined relationship in acute ischemic stroke. Cerebrovasc Dis 2015;40:59-66.

-17 Clua-Espuny JLI, Piñol-Moreso JLI, Gil-Guillén VF, Orozco-Beltrán D, Panisello-Tafalla A, Lucas-Noll J, QueraltTomás ML, Pla-Farnós R: Resultados de prevención cardiovascular primaria y secundaria en pacientes con ictus. Riesgo de recurrencia y supervivencia asociada. Estudio Ebrictus. Rev Neurol 2012;54:81-92.

18 Eriksson M, Carlberg B, Eliasson M: The disparity in long-term survival after a first stroke in patients with and without diabetes persists: The Northern Sweden MONICA Study. Cerebrovasc Dis 2012;34:153-160.

19 Silva GS, Lima FO, Camargo ECS, Smith WS, Lev MH, Harris GJ, Halpern EF, Koroshetz W, Furie KL: Gender differences in outcomes after ischemic stroke: role of ischemic lesion volume and intracranial large-artery occlusion. Cerebrovasc Dis 2010;30:470-475.

20 Flynn D, Nesbitt DJ, Ford GA, McMeekin P, Rodgers H, Price C, Kray C, Thomson RG: Development of a computerised decision aid for thrombolysis in acute stroke care. BMC Med Inform Decis Mak 2015;15:6.

21 Khatri P, Hacke W, Fiehler J, Saver JL, Diener H-C, Bendszus M, Bracard S, Broderick J, Campbell B, Ciccone A, Schonewille WJ, Siddiqui AH, Thomalla G, Tomsick TA, Turk AS, White PM, Zaidat OO, Liebeskind DS, Fulton R, Lees KR: State of acute endovascular therapy: report from the 12th Thrombolysis, Thrombectomy, and Acute Stroke Therapy Conference. Stroke 2015;46:1727-1734.

-22 Jovin TG, Chamorro A, Cobo E, de Miquel MA, Molina CA, Rovira A, San Roman L, Serena J, Abilleira S, Ribo M, Millan M, Urra X, Cardona P, Lopez-Cancio E, Tomasello A, Castano C, Blasco J, Aja L, Dorado L, Quesada H, Rubiera M, Hernandez-Perez M, Goyal M, Demchuk AM, von Kummer R, Gallofre M, Davalos A; for the REVASCAT Trial Investigators: Thrombectomy within $8 \mathrm{~h}$ after symptom onset in ischemic stroke. $\mathrm{N}$ Engl J Med 2015;372:2296-2306.

23 Hennerici MG: Is there a new era for stroke therapy? Cerebrovasc Dis 2015;40:I-II. 